\title{
Human Upper Epidermal Cytoplasmic Antibodies Are Directed against Keratin Intermediate Filament Proteins
}

\author{
Helmut Hintner, Peter M. Steinert, and Thomas J. Lawley, \\ Dermatology Branch, National Cancer Institute, National Institutes of \\ Health, Bethesda, Maryland 20205
}

A B S T R A C T Upper cytoplasmic (U-Cyt) antibodies are directed against cytoplasmic antigens found in keratinocytes in the upper layers of the epidermis. Until now, they have been defined by indirect immunofluorescence and are known to occur in the sera of patients with cutaneous diseases such as bullous dermatoses, basal cell carcinomas, and melanomas. An increased incidence of $\mathrm{U}$-Cyt antibodies has also been reported in the sera of patients with noncutaneous diseases, such as pulmonary neoplasms. They have been found in addition in the sera of some normal individuals. In this study we have identified keratin intermediate filaments (KIF) as antigens U-Cyt antibodies are directed against.

KIF proteins were prepared, separated by polyacrylamide gel electrophoresis, transblotted to nitrocellulose strips, and used as substrates for antibody binding. Sera containing U-Cyt antibodies by indirect immunofluorescence also had antibodies that were directed against high molecular weight $(65,000,63,000$, $61,500)$ KIF proteins. When KIF proteins were separated according to their charge and their molecular weight by two-dimensional gel electrophoresis and transblotted, the anti-KIF protein antibodies bound to virtually all charge isomers of the KIF proteins at the respective molecular weight. The antibody titers measured using the transblotting technique were 10 to 160 times higher than those found by indirect immunofluorescence. To determine whether U-Cyt antibodies were directed against KIF, a series of absorption and elution experiments were performed. Absorption of test sera with purified KIF removed both U-Cyt antibodies and anti-KIF protein antibodies. Absorption

Dr. Hintner is a recipient of a Max Kade Foundation Fellowship. Address all correspondence to Dr. Hintner.

Received for publication 22 December 1982 and in revised form 23 June 1983. with another type of intermediate filament derived from fibroblasts, vimentin, did not remove U-Cyt or anti-KIF protein antibodies. Absorbed U-Cyt and antiKIF protein antibodies were both eluted from the same KIF preparation and shown to bind to U-Cyt antigens by indirect immunofluorescence and KIF proteins by transblotting. Absorption of a serum containing U-Cyt antibodies, anti-nuclear antibodies, and anti-basement membrane zone antibodies with purified KIF resulted in the removal of the U-Cyt antibodies but not the other types of antibody. In addition, all test sera, even those that lacked U-Cyt antibodies, were found to have low-titer antibodies against KIF proteins by the transblotting technique. These data indicate that KIF proteins bear antigens to which U-Cyt antibodies are directed and that low titer antibodies against KIF proteins may be much more common than previously appreciated.

\section{INTRODUCTION}

Antibodies directed against cytoplasmic antigens of normal keratinocytes have been known for many years to be present in some normal sera as well as in the sera of patients with various cutaneous and noncutaneous diseases (1-5). Using the technique of indirect immunofluorescence it has been shown that one type of antigen(s) is present only in the cells of the upper layers of the human epidermis. These have been termed upper cytoplasmic antigens. The skin disorders, in which upper cytoplasmic (U-Cyt) ${ }^{1}$ antibodies are described, include blistering dermatoses such as pemphigus vul-

\footnotetext{
${ }^{1}$ Abbreviations used in this paper: DTT, dithiothreitol; HRP, horseradish peroxidase; HMW, high molecular weight; KIF, keratin intermediate filaments; PAGE, polyacrylamide gel electrophoresis; TBS, Tris-buffered saline; U-Cyt, upper cytoplasmic; WB, washing buffer.
} 
garis, bullous pemphigoid, and dermatitis herpetiformis as well as basal cell carcinomas and melanomas $(1,2,4,5)$. A high incidence of U-Cyt antibodies was also found in the sera of patients undergoing bone marrow transplants and patients with pulmonary and gastrointestinal neoplasms $(2,3)$. The exact nature of the antigens U-Cyt antibodies are directed against has been unknown. A series of observations, however, suggested the possibility that they may be differentiation products of human keratinocytes: $(a)$ The antigens are present in the upper layers but not in the basal cell layer of the epidermis (1-5); $(b)$ their presence has been noted in $45-65 \%$ of freshly isolated epidermal cells but in only $5-10 \%$ of cells grown in long-term primary culture or in secondary culture where epidermal cells fail to differentiate completely (6); and (c) they are also absent in tumors of the skin that lack fully differentiated keratinocytes (4). The major differentiation product of keratinocytes is keratin, and Fuchs and Green (7) demonstrated that the distribution of keratin intermediate filament (KIF) proteins is partially stratified in the epidermis on the basis of molecular weight. The inner layers of the epidermis contain only "small" $(46-58,000)$ keratin proteins, whereas the outer layers contain "large" $(63-67,000)$ keratins in addition to "small" keratins (7). These observations suggested the possibility that keratin proteins might be antigens of U-Cyt antibodies.

In this study we present evidence that KIF represent antigens towards which U-Cyt antibodies are directed. Moreover, U-Cyt antibodies bind preferentially to high molecular weight (HMW) proteins and to virtually all charge isomers of the respective KIF proteins.

\section{METHODS}

Isolation of KIF proteins. Strips of normal human skin ( $0.4 \mathrm{~mm}$ in thickness) were obtained from a surgical specimen by using a Castroviejo keratome (Storz Instrument Co., St. Louis, MO). The skin was cut into $5-\mathrm{mm}$ squares and incubated dermis side down in a $0.02 \mathrm{M}$ EDTA (8) buffer at $37^{\circ} \mathrm{C}$ for $3 \mathrm{~h}$. The epidermis was separated from the dermis and washed twice with phosphate-buffered saline (PBS). The epidermis was then minced into fine pieces and extracted in an $8 \mathrm{M}$ urea solution $\left(1 \mathrm{ml} / \mathrm{cm}^{2}\right)$ containing 0.1 $\mathrm{M}$ Tris- $\mathrm{HCl}$ ( $\mathrm{pH} \mathrm{9.0)}$ and $0.1 \mathrm{M}$ 2-mercaptoethanol for $4 \mathrm{~h}$ at room temperature (9). After removing the cellular debris by centrifugation at $15,000 \mathrm{rpm}$ for $30 \mathrm{~min}$ at $4^{\circ} \mathrm{C}$, the supernatant was dialyzed at room temperature overnight against a buffer containing $0.025 \mathrm{M}$ Tris- $\mathrm{HCl}(\mathrm{pH} 8.3), 0.192$ $\mathrm{M}$ glycine, $0.1 \%$ sodium dodecyl sulfate (SDS), and $0.025 \mathrm{M}$ 2-mercaptoethanol and processed for SDS-polyacrylamide gel electrophoresis (PAGE).

Repolymerization of KIF from isolated KIF proteins. A portion of the KIF protein solution was chromatographed on a Sepharose CL-4B-200 (Sigma Chemical Co., St. Louis, $\mathrm{MO}$ ) column in a $0.025 \mathrm{M}$ Tris- $\mathrm{HCl}(\mathrm{pH} \mathrm{8.3)}, 0.192 \mathrm{M}$ glycine, $0.1 \%$ SDS, $0.001 \mathrm{M}$ EDTA, and $0.001 \mathrm{M}$ dithiothreitol (DTT) buffer. By this technique, the KIF proteins were sep- arated from the HMW histidine-rich proteins that are also extracted from the epidermis. These proteins may interfere with KIF reassembly in vitro (P. M. Steinert, unpublished data). Subsequently, fractions containing exclusively KIF proteins were freed of bound SDS as described previously (10). The proteins were then redissolved in urea buffer (see above) and dialyzed against $1,000 \mathrm{vol}$ of $0.005 \mathrm{M}$ Tris- $\mathrm{HCl}$ buffer ( $\mathrm{pH}$ 7.6) containing 0.001 M EDTA and 0.001 M DTT to repolymerize the KIF in vitro (11). This was followed by negative staining with $0.7 \%$ uranyl acetate for the electron microscopic visualization. In one experiment, the washed pellet of KIF was redissolved in SDS and the constituent proteins were separated by SDS-PAGE.

SDS-PAGE. SDS-PAGE was performed by the method of Laemmli (12). 10- $\mu 1$ aliquots of the same KIF protein solution $(3.0 \mathrm{mg} / \mathrm{ml})$ were used for SDS-PAGE throughout all experiments.

Two-dimensional gel electrophoresis of KIF proteins. Two-dimensional gel electrophoresis of KIF proteins was performed according to O'Farrell (13). Ampholytes (Bio-Rad Laboratories, Richmond, $\mathrm{CA}$ ) with a $\mathrm{pH}$ range from 3 to 10 were used for tube gel isoelectric focusing; the second dimension was performed in a $7.5 \%$ continuous polyacrylamide gel.

Protein transblotting to nitrocellulose sheets. Transfer of the proteins from SDS gels to nitrocellulose sheets (TransBlot TM Transfer Medium, Bio-Rad Laboratories) was performed as described by Towbin et al. (14). After a transblotting time of $>15 \mathrm{~h}$ at $4^{\circ} \mathrm{C}(60 \mathrm{~V}, 0.22 \mathrm{~A}$, transfer buffer $0.025 \mathrm{M}$ Tris-HCl (pH 8.3), $0.192 \mathrm{M}$ glycine, $20 \%$ methanol) the nitrocellulose sheets were cut into individual lanes that contained either HMW standard proteins (Bio-Rad Laboratories) or the KIF polypeptides. The lanes were then processed for various immunological procedures. In every transblotting experiment two of the appropriate lanes were stained with amido black to demonstrate the transfer of all proteins. Also, after transblotting, the polyacrylamide gels were stained with Coomassie Blue to detect nontransferred proteins.

Test sera. The sera of 12 normal laboratory personnel (sera Nos. 1 to 12) and of seven patients with dermatological disorders (two patients with dermatitis herpetiformis, sera Nos. 13 and 14, two with cicatricial pemphigoid, sera Nos. 15 and 16, one with bullous pemphigoid, serum No. 17, and two with pemphigus vulgaris, sera Nos. 18 and 19) were studied for the presence of U-Cyt or anti-KIF protein antibodies. All sera were either freshly drawn or had been stored at $-70^{\circ} \mathrm{C}$.

Demonstration of antibody binding to transblotted KIF proteins. Individual lanes of nitrocellulose membranes to which KIF proteins had been previously transblotted were washed with Tris-buffered saline (TBS; $0.15 \mathrm{M} \mathrm{NaCl}, 0.01$ $\mathrm{M}$ Tris- $\mathrm{HCl}, \mathrm{pH}$ 7.4) containing $3 \%$ (wt/vol) bovine serum albumin (BSA) for $2 \mathrm{~h}$ and were then incubated for $2 \mathrm{~h}$ with $2.5 \mathrm{ml}$ of various dilutions of the test sera. To exclude a prozone phenomenon and to detect changes in staining patterns, a series of dilutions of test sera ranging from 50 to 5,000 and, if necessary higher, was utilized. After six washes with washing buffer (WB; $0.3 \mathrm{M} \mathrm{NaCl}, 0.01 \mathrm{M}$ Tris- $\mathrm{HCl}, \mathrm{pH}$ $7.4,0.5 \%$ Nonidet $P-40$, Sigma Chemical Co.) for $5 \mathrm{~min}$, the nitrocellulose strips were incubated with $2.5 \mathrm{ml}$ of horseradish peroxidase-conjugated staphylococcal Protein A (HRPProtein A, Kirkegaard and Perry Lab, Gaithersburg, MD) at a 1:200 dilution for $2 \mathrm{~h}$. This was followed by five more washes with WB and two with TBS. The binding of HRPProtein $A$ was then visualized by incubation of the nitrocellulose strips with diaminobenzidine medium (15) for 30 
min and the reaction stopped by three 10-min washes with TBS. Test sera and the HRP-Protein A were diluted with WB containing $3 \% \mathrm{BSA}$, all incubations were performed at room temperature. For control purposes, the test serum was substituted by WB containing 3\% BSA. In a series of experiments, the KIF proteins were transblotted from the twodimensional gels to nitrocellulose sheets and autoantibody binding on them was demonstrated as described above.

Indirect immunofluorescence of upper cytoplasmic antibodies. The demonstration of circulating antibodies directed against U-Cyt antigens by indirect immunofluorescence was performed as previously described (16).

Absorption and elution studies. $0.5 \mathrm{ml}$ of sera Nos. 1 and 2 were each mixed with $0.5 \mathrm{ml}$ of suspension of purified KIF $(1.5 \mathrm{mg} / \mathrm{ml})$ and tumbled at room temperature for $\mathrm{l} \mathrm{h}$. After centrifugation at $15,000 \mathrm{rpm}$ for $1 \mathrm{~h}, 0.5 \mathrm{ml}$ of the supernatant was then mixed with $0.5 \mathrm{ml}$ of the KIF suspension and the absorption procedure was repeated. The final supernatants were then processed for the demonstration of the remaining U-Cyt antibodies by indirect immunofluorescence or antibodies against KIF proteins by the transblotting technique as described above. In one experiment, the absorbed antibodies were eluted from the KIF by incubating the washed KIF pellet with $1 \mathrm{ml}$ of $0.1 \mathrm{M}$ glycine-HCl buffer $\mathrm{pH} 3.0$ for $15 \mathrm{~min}$ at room temperature. After neutralization with $0.1 \mathrm{~N} \mathrm{NaOH}$ and centrifugation at 5,000 rpm for 10 min, the supernatant was dialyzed against PBS overnight and then checked for U-Cyt antibodies by indirect immunofluorescence and for antibodies to transblotted KIF proteins. Controls included substitution of the KIF suspension by $0.5 \mathrm{ml}$ of the reconstitution dialysis buffer (see above) or by an equal amount of vimentin extracted from mouse 3T3 cells or human fibroblasts (17). 3T3 cells and human fibroblasts were grown under routine culture conditions and the intermediate filaments extracted by the method described by Steinert et al. (9). To demonstrate the specificity of UCyt antibody absorption by KIF, a serum containing bullous pemphigoid anti-basement membrane zone antibodies and anti-nuclear antibodies as well as U-Cyt antibodies was absorbed by a suspension of purified KIF and examined for remaining reactivity of the respective antibodies as already described. Since the titer of the basement membrane zone antibodies (original titer 1:1,280) exceeded the titer of antinuclear (1:80) and U-Cyt antibodies (1:40) markedly, an additional absorption experiment was performed in which the test serum was diluted so that basement membrane zone antibodies were in a concentration range comparable to the U-Cyt antibody titer.

\section{RESULTS}

Separation of KIF proteins by PAGE and reassembly into filaments. Analytical SDS-PAGE of the freshly isolated KIF proteins or KIF proteins redissolved from reconstituted KIF demonstrated the presence of low $(51,000,54,000,55,000,58,000$, and $60,000)$ and high $(61,500,63,000$, and 65,000$)$ molecular weight proteins in a pattern similar to that described by others $(7,18)$ (Fig. 1, A-C). Dialysis of these KIF proteins into reconstitution buffer as described (11) led to the in vitro formation of curvilinear, unbranched filaments that were $\sim 10 \mathrm{~nm}$ in diameter and several micrometers long, and often formed clusters of multiple KIF.

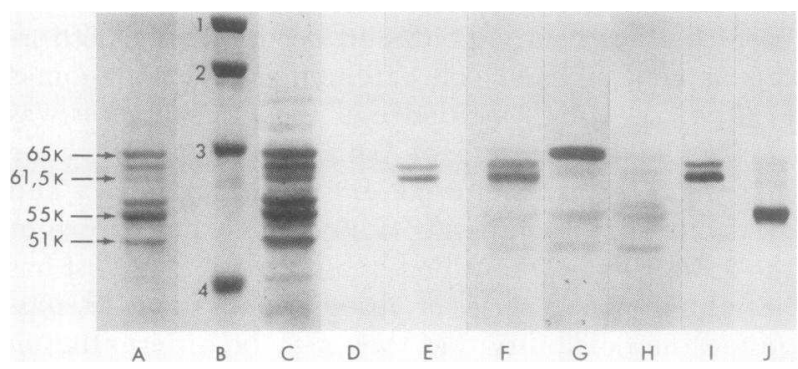

FIgURE 1 (Lane A) PAGE of KIF proteins stained with Coomassie Blue: KIF proteins exhibit a molecular weight range from 51,000 to 65,000 . (Lane $B$ ) PAGE of molecular weight standards including: $1, \beta$-galactosidase, 116,$250 ; 2$, phosphorylase $B, 92,500 ; 3, \mathrm{BSA}, 66,000 ; 4$, ovalbumin, 45,000, stained with Coomassie Blue. (Lane C) The distribution pattern of KIF proteins after transblotting to nitrocellulose sheets and staining with amido black. Lanes $E-J$ represent individual nitrocellulose strips, transblotted with KIF proteins, incubated with various test sera, and stained with HRP-Protein A. Note strong staining of the 61,500 and $63,000 \mathrm{KIF}$ protein band in lanes $E$ (serum No. 2, 1:100), $F$ (serum No. 1, 1:50), and $I$ (serum No. 17, 1:400); the 65,000 band in lane $G$ (serum No. 4, 1:100), the 55,000 band in lane $J$ (serum No. 13, 1:200); and faint staining of low molecular weight KIF proteins in lanes $F$ and $G$, of HMW KIF proteins in $J$, as well as of high and low molecular weight KIF proteins in $H$ (serum No. 8, 1:100). (Lane $D$ ) Substitution of the test serum by $3 \%$ BSA WB followed by HRP-Protein A did not result in any staining.

Transfer of KIF proteins to nitrocellulose. Transblotting of the KIF proteins from the polyacrylamide gels to nitrocellulose sheets revealed an identical pattern of distribution of the protein bands when the nitrocellulose strips, stained with amido black (Fig. $1 \mathrm{C}$ ) were compared with the Coomassie Blue-stained polyacrylamide gels (Fig. $1 \mathrm{~A}$ ). Examination of the polyacrylamide gels after transblotting revealed generally complete transfer of the proteins.

Detection of U-Cyt antibodies and their antigens. 12 normal human sera and seven sera of patients with skin diseases were examined for the presence of $\mathrm{U}$-Cyt antibodies first using the traditional method of indirect immunofluorescence and then by HRP-Protein A staining of KIF proteins transblotted to nitrocellulose strips that had been preincubated with serial dilutions of the same 19 sera. Indirect immunofluorescence demonstrated that five of 12 normal human sera and all seven patient sera possessed U-Cyt antibodies (Fig. 2). The titers ranged from 1:5 to $1: 320$ (Table I). When the test sera were examined for antibodies to KIF proteins, all 12 normal and all seven patient sera had antibodies against one or more of the KIF protein bands (Table I; Fig. $1, E-J)$. When the titers of the anti-KIF protein antibodies and the pattern of the specific KIF proteins stained were examined, several points became evident. The transblotting method is from 10 to 160 times more 


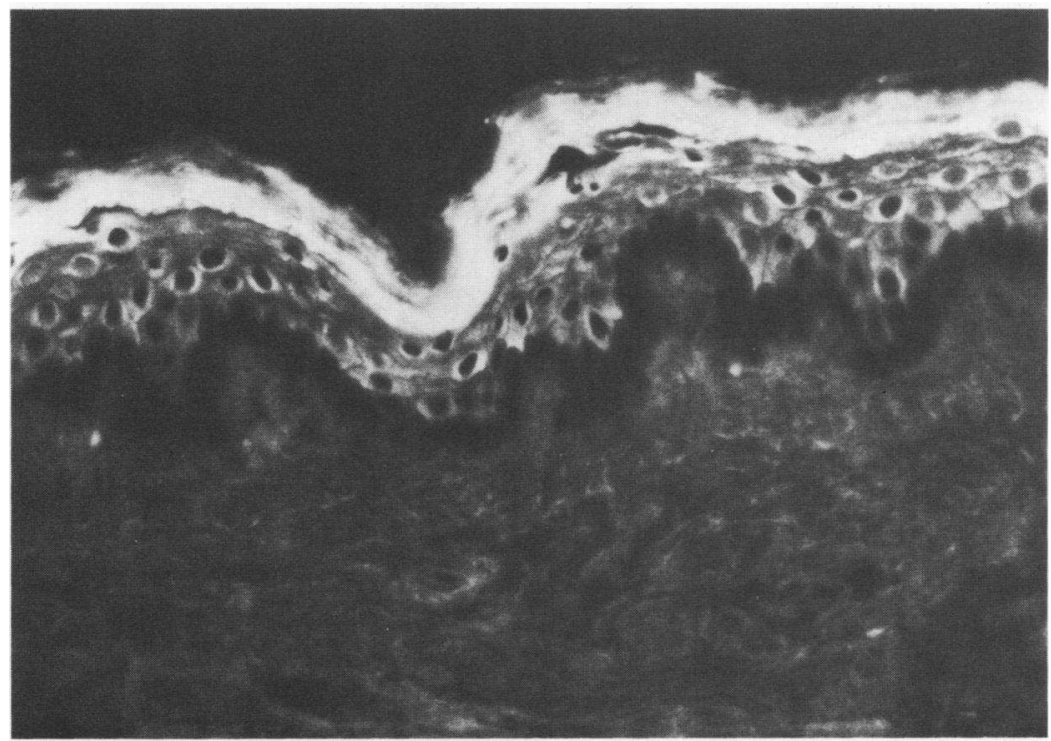

FIGURE 2 Indirect immunofluorescence of normal human skin with a 1:5 dilution of serum No. 1 and fluorescein isothiocyanate-conjugated goat anti-human IgG at 1:40 shows bright cytoplasmic staining of upper keratinocytes. Basal keratinocytes, in contrast, remain unstained. $\times 250$.

sensitive than indirect immunofluorescence of human skin in the detection of U-Cyt antibodies. As a group, the 12 individuals (five normal subjects, seven pa- tients), who were positive for U-Cyt antibodies by indirect immunofluorescence had higher titers of anti KIF protein antibodies by the transblotting technique

TABLE I

Profile and Titer of Anti-KIF Protein Antibodies

\begin{tabular}{|c|c|c|c|c|c|c|c|}
\hline \multicolumn{7}{|c|}{ Immunoblot } & \multirow{2}{*}{$\frac{\text { Indirect immunofluorescence }}{\text { U-Cyt antibody titer }}$} \\
\hline \multicolumn{7}{|c|}{ Molecular weights of KIF proteins } & \\
\hline Serum & 65,000 & 63,000 & 61,500 & 58,000 & 55,000 & 51,000 & - \\
\hline $1^{\circ}$ & $200 \rrbracket$ & 5,000 & 5,000 & - & 100 & 100 & $1: 40$ \\
\hline $2^{\circ}$ & 100 & 1,000 & 1,000 & - & 100 & - & $1: 40$ \\
\hline $3^{\circ}$ & 800 & 800 & 800 & - & - & 400 & $1: 10$ \\
\hline $4^{\circ}$ & 800 & 200 & - & - & 200 & 200 & 1:5 \\
\hline $5^{\circ}$ & 100 & 400 & 400 & - & - & 400 & 1:5 \\
\hline 6 & - & - & - & 100 & - & - & - \\
\hline 7 & 100 & - & - & 200 & - & - & - \\
\hline 8 & 100 & 200 & 200 & 200 & 200 & 200 & - \\
\hline 9 & 100 & 100 & 100 & - & 200 & 100 & - \\
\hline 10 & - & - & - & 100 & 100 & - & - \\
\hline 11 & - & - & - & - & 200 & 100 & - \\
\hline 12 & - & 50 & 50 & - & 50 & - & - \\
\hline $13^{\circ}$ & 200 & 200 & 400 & - & 12,800 & - & $1: 320$ \\
\hline $14^{\circ}$ & 400 & 800 & 800 & - & 800 & - & $1: 10$ \\
\hline $15^{\circ}$ & 50 & 400 & 400 & - & 200 & - & $1: 40$ \\
\hline $16^{\circ}$ & 800 & 800 & 800 & - & 800 & - & $1: 80$ \\
\hline $17^{\circ}$ & 100 & 6,400 & 3,200 & - & 100 & - & $1: 40$ \\
\hline $18^{\circ}$ & 400 & 800 & 1,600 & - & 100 & - & $1: 40$ \\
\hline $19^{\circ}$ & 800 & 400 & 400 & - & 100 & - & $1: 20$ \\
\hline
\end{tabular}

- Sera of individuals positive for U-Cyt by indirect immunofluorescence.

$\downarrow$ Titer of anti-KIF protein antibodies. 
than the seven who were negative by indirect immunofluorescence. In addition, the pattern of KIF protein staining, a function of the molecular weights of the various proteins, was quite different between the U-Cyt positive and U-Cyt negative individuals (Table I). In the group positive for U-Cyt antibodies by indirect immunofluorescence, all individuals possessed high titer $(\geqslant 400)$ antibodies directed against one or several of the HMW $(65,000,63,000$, and 61,500$)$ KIF proteins (Fig. 1, E-G, I). In three of the patient sera high titer $(>400)$ antibodies against the 55,000-mol wt KIF protein were also detectable (Fig. $1 \mathrm{~J}$ ). In contrast, none of the seven individuals who were negative for U-Cyt antibodies by indirect immunofluorescence possessed high titer antibodies by the transblotting technique against any of the KIF proteins; however, they did stain some KIF protein bands (Fig. $1 H$ ). The major portion of the anti-KIF protein antibodies in the UCyt antibody negative sera was directed against low molecular weight KIF proteins.

Absorption and elution studies. To examine the specificity of U-Cyt antibodies, a series of absorption studies was performed using purified reconstituted KIF as the substrate and a nonkeratinocyte intermediate filament protein, vimentin (17), as a control. Absorption of two normal sera with high titer anti-KIF protein antibodies with purified KIF resulted in complete abolition of U-Cyt antibody staining by indirect immunofluorescence (Fig. $3, A$ and $B$ ). In addition, there was no reactivity of one of the absorbed sera (No. 2) with KIF proteins (Fig. 3, C and D) and only a faint hue of residual staining with the second absorbed serum (No. 1) after transblotting. The antibodies absorbed by the KIF were eluted with an acid glycine buffer and neutralized. The eluted antibodies demonstrated U-Cyt antibody staining in indirect immunofluorescence. In addition, they reacted with the same respective HMW KIF proteins that were stained by the unabsorbed serum. Control absorptions, including the substitution of the KIF by vimentin intermediate filaments extracted from mouse $3 \mathrm{~T} 3$ cells or from human fibroblasts, showed no significant change in the binding of U-Cyt antibodies by indirect immunofluorescence or anti-KIF protein antibodies by transblotting. Absorption of an appropriately diluted bullous pemphigoid patient serum that contained anti-basement membrane zone antibodies, anti-nuclear antibodies, and U-Cyt antibodies, with KIF, resulted in removal of U-Cyt antibodies but no change in binding of the antibodies against basement membrane zone or nuclear antigens.

Binding of anti-KIF protein antibodies to KIF proteins separated by two-dimensional gel electrophoresis. When KIF proteins from normal human epidermis were separated by two-dimensional gel elec-
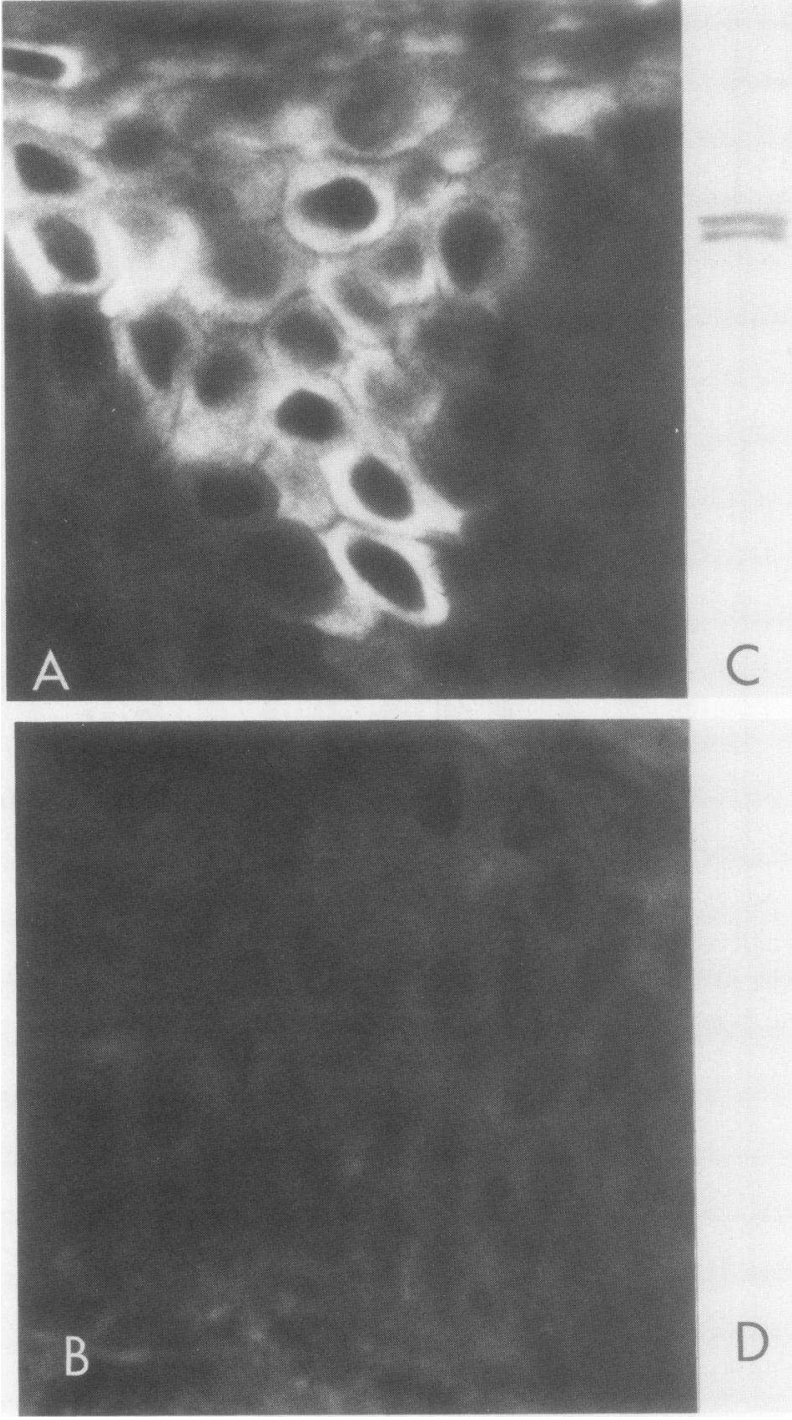

Figure 3 (A) A biopsy of normal human skin showing UCyt antibody staining after incubation with a 1:5 dilution of serum No. 2 followed by fluorescein isothiocyanate-conjugated goat anti-human IgG. Bright cytoplasmic immunofluorescence of the upper keratinocytes contrasts the lack of reactivity of basal keratinocytes. $(B)$ No specific staining is detectable when serum No. 2 was absorbed on KIF before the performance of the indirect immunofluorescence procedure described in $\mathrm{A}$. ( $C$ and $D$ ) Nitrocellulose strips, containing KIF proteins, were incubated first with serum No. 2 in a dilution of $1: 100(C)$ or serum No. 2 absorbed on KIF, also diluted 1:100 $(D)$, followed by HRP-Protein $A$ in a dilution of 1:200. Distinct staining of the 61,500 and the 63,000 mol wt KIF protein bands is seen in $C$, whereas a complete lack of reactivity is demonstrated in $D$. $A$ and $B, \times 835$.

trophoresis according to their pI values and their molecular weights, a distribution pattern of individual KIF polypeptides was obtained similar to the one de- 
scribed by Bladon et al. (19) and Moll et al. (20). HMW KIF proteins were distributed over a wide range from $\mathrm{pH} 6.0$ to 8.0. Low molecular weight KIF proteins were mainly found in a neutral region ( $\mathrm{pH} 6.3$ ) and in an acidic region ( $\mathrm{pH}$ 5.0) (Fig. $4 \mathrm{~A}$ ). Antibodies to KIF proteins bound to virtually all charge isomers of individual KIF proteins at a given molecular weight (Fig. $4 B$, serum No. 4 , and $C$, serum No. 2). The staining with the anti-KIF antibodies proved to be a very sensitive technique in the detection of KIF proteins since some of them have been more heavily stained by the HRP reaction product than they were by Coomassie Blue (Fig. $4 \mathrm{~A}$ ) or amido black staining of the same protein preparation.

\section{DISCUSSION}

Since proteins can be transferred from analytical SDS gels to nitrocellulose sheets $(14,21)$ and can then be used as substrates for immunological reactions, it was possible to determine which, if any, of the KIF proteins extracted from human epidermal cells are reactive with U-Cyt antibodies. Our results demonstrated that individuals who possess U-Cyt antibodies also have

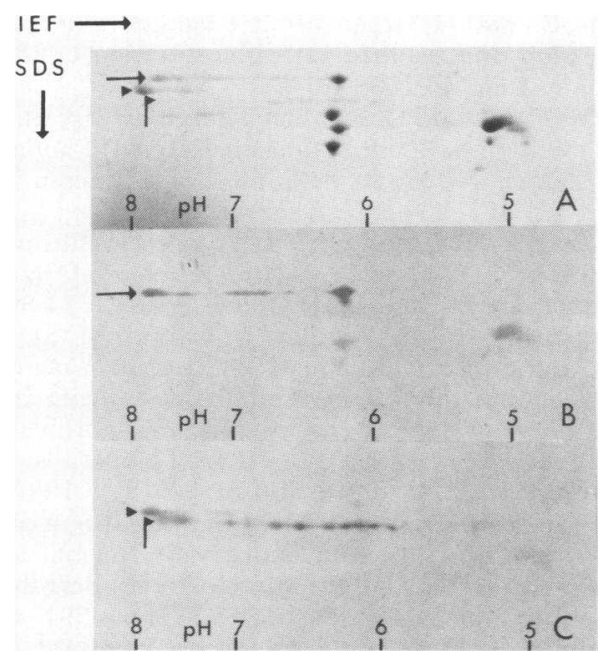

Figure 4 Binding of anti-KIF antibodies on KIF proteins that have been separated by two-dimensional polyacrylamide gel electrophoresis and transblotted to nitrocellulose sheets. Virtually all KIF proteins in the respective molecular weight are distinctively stained $(B$ : serum No. 4, $C$ : serum No. 2); binding is shown by the use of HRP-conjugated protein A. The distribution of HMW KIF proteins over the pH range from 6.0 to 8.0 and of low molecular weight KIF proteins, which focus in a neutral region of $\mathrm{pH} 6.3$ and in an acidic region of pH 5.0 is depicted on a gel stained with Coomassie Blue $(A)$. Straight arrow, 65,000 KIF proteins; arrow head: $63,000 \mathrm{KIF}$ proteins; flag arrow: $61,500 \mathrm{KIF}$ proteins. high titer antibodies directed against HMW and in some instances the 55,000-mol wt KIF protein. The binding of antibodies to individual KIF proteins varied somewhat from serum to serum as indicated by differences in binding patterns and antibody titers. For instance, high titer anti-KIF protein antibodies in sera Nos. 1, 2, and 17 bound strongly to the 63,000 - and 61,500 -mol wt (Fig. $1 E, F$, and $I$ ), in serum No. 4 to the $65,000-\mathrm{mol}$ wt (Fig. $1 \mathrm{G}$ ) and in serum No. 13 to the 55,000-mol wt KIF protein (Fig. $1 J$ ). The preferential binding of antibodies to individual KIF proteins or KIF protein groups has been also observed by Woodcock-Mitchell et al. (18) who used several different monoclonal antibodies for the demonstration of a distinct distribution pattern of KIF proteins within the human epidermis. The finding of variation in KIF proteins stained in immunblot can be reconciled with the finding of monotonous U-Cyt staining by indirect immunofluorescence by the fact that all of the heavily stained KIF proteins $(65,000,63,000,61,500$, and $55,000)$ are present mainly in the upper layers of the epidermis $(7,18)$. This finding suggests that these KIF proteins represent antigens which U-Cyt antibodies are directed against.

It is known that the various KIF proteins, as defined by their molecular weight on one-dimensional PAGE actually represent groups or "families" of KIF proteins with the same molecular weight but different charge characteristics $(19,20)$. Therefore, in order to further define the KIF antigens, we separated KIF proteins according to their charge and molecular weight by two-dimensional gel electrophoresis, transblotted them to nitrocellulose sheets, and reacted them with two of our test sera. Anti-KIF antibodies reacted with virtually all individual KIF proteins of a particular molecular weight over a wide pI range (Fig. 4). This indicates that these proteins retain common antigenic determinants despite significant differences in individual charges, which are thought to be the result of their degree of phosphorylation (22).

To further elucidate the relation of KIF proteins to U-Cyt antibodies, we performed a series of absorption and elution experiments with purified preparations of KIF and sera containing U-Cyt antibodies. Absorption of sera with KIF abolished the staining of U-Cyt antigens by indirect immunofluorescence and of KIF proteins after transblotting (Fig. 3). The fact that UCyt antibodies and anti-KIF protein antibodies could be absorbed by purified KIF but not by preparations of another type of intermediate filament, vimentin, is evidence that KIF proteins bear antigens against which U-Cyt antibodies are directed. The ability to elute these antibodies from KIF after their absorption to $\mathrm{KIF}$ and to demonstrate their staining of U-Cyt antigens on indirect immunofluorescence and of KIF pro- 
teins after transblotting further buttresses this finding. Finally, the observation that purified KIF preparations did not absorb other unrelated antibodies such as the anti-basement membrane zone antibodies of bullous pemphigoid or anti-nuclear antibodies, but did absorb the U-Cyt antibodies in the same serum, also attests to the immunological specificity of the binding of the U-Cyt antibodies to the KIF.

It was also of interest that besides the 12 test sera, which exhibited U-Cyt antibodies by indirect immunofluorescence, and high titer anti-KIF antibodies by transblot, the seven other test sera that did not contain U-Cyt antibody activity by indirect immunofluorescence did demonstrate a faint staining of various KIF proteins. This finding suggests that all of these individuals possess antibodies directed against KIF proteins and raises the intriguing possibility that all individuals may possess antibodies against keratin. In fact there has been a recent series of reports documenting the existence of antibodies against various types of intermediate filaments such as desmin, vimentin, keratin, and neurofilaments in the sera of patients with diseases such as measles, infectious mononucleosis, hepatitis B, Waldenström's macroglobulinemia, rheumatoid arthritis, and systemic lupus erythematosus (23-29). However, the pathophysiologic significance of these antibodies is unclear and there is no compelling evidence that they play a significant role in the pathophysiology of any of these diseases. Our observation of anti-KIF antibodies in 12 of 12 normal sera combined with the finding of Senecal et al. (24) that $50 \%$ of normal individuals studied with indirect immunofluorescence have IgM antibodies against the intermediate filament vimentin, suggests that such antibodies may be very common and not limited to disease states. That they have been detected more readily in disease states in the past may be a function of higher titers of antibodies in individuals undergoing tissue damage (25). In addition, since transblotting is from 10 to 160 times more sensitive than indirect immunofluorescence, use of this technique on a wider scale may result in the detection of intermediate filament antibodies in the majority or perhaps all human sera. This would parallel the observation of Osborn et al. (30) who found naturally occurring antibodies against intermediate filaments in 28 of 30 normal, nonimmunized rabbits.

The presence of antibodies to KIF proteins in all normal sera that were studied makes it unlikely that they play a role in a specific disease process. Rather it seems reasonable that such a system of antibodies may be formed in response to the liberation of antigens after epithelial cell injury or death. These antibodies may play a role in maintaining homeostasis by aiding in the removal or opsonization of such insoluble pro- teins from damaged tissue or in wound healing or other mechanisms of tissue repair.

\section{ACKNOWLEDGMENTS}

We thank Dr. John Stanley for his helpful advice and Mrs. Naomi Spalding for the preparation of the manuscript.

\section{REFERENCES}

1. Abel, E. A., and J.-C. Bystryn. 1976. Epidermal cytoplasmic antibodies: incidence and type in normal persons and patients with melanoma. J. Invest. Dermatol. 66:44-48.

2. Paluch, E. P., and K. J. Bloch. 1982. Antibodies to human epidermal cytoplasmic antigens: incidence, patterns, and titers. J. Invest. Dermatol. 79:115-118.

3. Janin-Mercier, A., J. H. Saurat, and L. Didierjean. 1978. Epidermal cytoplasmic antibodies as detected by HRPlabelled antisera. Arch. Dermatol. Res. 262:235-238.

4. Bystryn, J.-C., M. Nash, and P. Robins. 1978. Epidermal cytoplasmic antigens. II. Concurrent presence of antigens of different specificities in normal human skin. $J$. Invest. Dermatol. 71:110-113.

5. Burnham, T. K. 1974. Two epidermal cytoplasmic immunofluorescent patterns detected by indirect immunofluorescence. J. Invest. Dermatol. 63:100-105.

6. Faure, M., M. Eisinger, and J.-C. Bystryn. 1981. Decreased expression of epidermal cytoplasmic antigens in cultured human keratinocytes. J. Invest. Dermatol. 76:347-351.

7. Fuchs, E., and H. Green. 1980. Changes in keratin gene expression during terminal differentiation of the keratinocyte. Cell. 19:1033-1042.

8. Scaletta, L. J., and D. K. MacCallum. 1972. A fine structural study of divalent cation-mediated epithelial union with connective tissue in human oral mucosa. Am. J. Anat. 133:431-454.

9. Steinert, P., R. Zackroff, M. Aynardi-Whitman, and R. D. Goldman. 1982. Isolation and characterization of intermediate filaments. Methods Cell Biol. 24:399-419.

10. Steinert, P. M., W. W. Idler, F. Cabral, M. M. Gottesman, and R. D. Goldman. 1981. In vitro assembly of homopolymer and copolymer filaments from intermediate filament subunits of muscle and fibroblast cells. Proc. Natl. Acad. Sci. USA. 78:3692-3696.

11. Steinert, P. M., G. L. Peck, and W. W. Idler. 1980. Structural changes of human epidermal $\alpha$-keratin in disorders of keratinization. In Biochemistry of Normal and Abnormal Epidermal Differentiation. I. A. Bernstein and M. Seiji, editors. University Press, Tokyo. 391-406.

12. Laemmli, U. K. 1970. Cleavage of structural proteins during the assembly of the head of bacteriophage $T_{4}$. Nature (Lond.). 277:680-685.

13. O'Farrell, P. H. 1975. High resolution two-dimensional electrophoresis of proteins. J. Biol. Chem. 250:40074021.

14. Towbin, H., T. Staehelin, and J. Gordon. 1979. Electrophoretic transfer of proteins from polyacrylamide gels to nitrocellulose sheets: procedure and some applications. Proc. Natl. Acad. Sci. USA. 76:4350-4354.

15. Graham, R. C., Jr., and M. J. Karnovsky. 1966. The early stages of absorption of injected horseradish peroxidase in the proximal tubules of mouse kidney. Ultrastructural cytochemistry by a new technique. J. Histochem. Cytochem. 14:291-302. 
16. Hintner, H., G. Stingl, G. Schuler, and K. Wolff. 1982. In vitro complement-binding on cytoplasmic structures in normal human skin. I. Immunofluorescence studies. J. Invest. Dermatol. 79:119-124.

17. Franke, W. W., E. Schmid, M. Osborn, and K. Weber. 1978. Different intermediate-sized filaments distinguished by immunofluorescence microscopy. Proc. Natl. Acad. Sci. USA. 75:5034-5038.

18. Woodcock-Mitchell, J., R. Eichner, W. G. Nelson, and T. T. Sun. 1982. Immunolocalization of keratin polypeptides in human epidermis using monoclonal antibodies. J. Cell Biol. 95:580-588.

19. Bladon, P. T., P. E. Bowden, W. J. Cunliffe, and E. J. Wood. 1982. Prekeratin biosynthesis in human scalp epidermis. Biochem. J. 208:179-187.

20. Moll, R., W. W. Franke, D. L. Schiller, B. Geiger, and R. Krepler. 1982. The catalog of human cytokeratins: patterns of expression in normal epithelia, tumors and cultured cells. Cell. 31:11-24.

21. Burnette, W. N. 1981. "Western Blotting": electrophoretic transfer of proteins from sodium dodecyl sulfatepolyacrylamide gels to unmodified nitrocellulose and radiographic detection with antibody and radioiodinated Protein A. Anal. Biochem. 112:195-203.

22. Gilmartin, M. E., V. B. Culbertson, and I. M. Freedberg. 1980. Phosphorylation of epidermal keratins. J. Invest. Dermatol. 75:211-216.

23. Kurki, P., I. Virtanen, S. Stenman, and E. Linder. 1978. Characterization of human smooth muscle autoantibodies reacting with cytoplasmic intermediate filaments. Clin. Immunol. Immunopathol. 11:379-387.
24. Senecal, J. L., N. F. Rothfield, and J. M. Oliver. 1982. Immunoglobin $\mathrm{M}$ autoantibody to vimentin intermediate filaments. J. Clin. Invest. 69:716-721.

25. Pedersen, J. S., B. H. Toh, S. A. Locarnini, I. D. Gust, and G. N. S. Shyamala. 1981. Autoantibody to intermediate filaments in viral hepatitis. Clin. Immunol. Immunopathol. 21:154-161.

26. Dellagi, K., J. C. Brouet, J. Perreau, and D. Paulin. 1982. Human monoclonal IgM with autoantibody activity against intermediate filaments. Proc. Natl. Acad. Sci. USA. 79:446-450.

27. Linder, E., M. Hormia, V. P. Lehto, and T. Törnroth. 1981. Identification of cytoskeletal intermediate filaments of vascular endothelial cells as targets for autoantibodies in patients sera. Clin. Immunol. Immunopath. 21:217-227.

28. Toh, B. H., A. Yildiz, J. Sotelo, J. Osung, E. J. Holborow, F. Kanakoudi, and J. V. Small. 1979. Viral infections and IgM autoantibodies to cytoplasmic intermediate filaments. Clin. Exp. Immunol. 37:76-82.

29. Sotelo, J., C. J. Gibbs, Jr., and D. C. Gajdusek. 1980. Autoantibodies against axonal neurofilaments in patients with Kuru and Creutzfeldt-Jakob disease. Science (Wash. DC). 210:190-193.

30. Osborn, M., W. W. Franke, and K. Weber. 1977. Visualization of a system of filaments 7-10 nm thick in cultured cells of an epitheloid line (PtK2) by immunofluorescence microscopy. Proc. Natl. Acad. Sci. USA. 74:2490-2494. 